\title{
Molecular Mechanisms of Lipoic Acid Modulation of T-Type Calcium Channels in Pain Pathway
}

\author{
Woo Yong Lee, ${ }^{1,2 *}$ Peihan Orestes, ${ }^{2,5 *}$ Janelle Latham, ${ }^{2}$ Ajit K. Naik, ${ }^{2}$ Michael T. Nelson, ${ }^{2,5}$ Iuliia Vitko, \\ Edward Perez-Reyes, ${ }^{4,5}$ Vesna Jevtovic-Todorovic, ${ }^{2,3,5}$ and Slobodan M. Todorovic ${ }^{2,3,5}$ \\ ${ }^{1}$ Department of Anesthesiology and Pain Medicine InJe University, Sanggyepaik Hospital, Seoul 139-707, South Korea, Departments of ${ }^{2}$ Anesthesiology, \\ ${ }^{3}$ Neuroscience, and ${ }^{4}$ Pharmacology, and ${ }^{5}$ Neuroscience Graduate Program, University of Virginia School of Medicine, Charlottesville, Virginia 22908-0710
}

$\alpha$-Lipoic acid (1,2-dithiolane-3-pentanoic acid; lipoic acid) is an endogenous compound used to treat pain disorders in humans, but its mechanisms of analgesic action are not well understood. Here, we show that lipoic acid selectively inhibited native $\mathrm{Ca}_{\mathrm{V}} 3.2 \mathrm{~T}$-type calcium currents (T-currents) and diminished T-channel-dependent cellular excitability in acutely isolated rat sensory neurons. Lipoic acid locally injected into peripheral receptive fields of pain-sensing sensory neurons (nociceptors) in vivo decreased sensitivity to noxious thermal and mechanical stimuli in wild-type but not $\mathrm{Ca}_{\mathrm{v}} 3.2$ knock-out mice. Ensuing molecular studies demonstrated that lipoic acid inhibited recombinant $\mathrm{Ca}_{\mathrm{v}} 3.2$ channels heterologously expressed in human embryonic kidney 293 cells by oxidating specific thiol residues on the cytoplasmic face of the channel. This study provides the first mechanistic demonstration of a nociceptive ion channel modulation that may contribute to the documented analgesic properties of lipoic acid in vivo.

\section{Introduction}

It has been estimated that acute and chronic pain requiring medical treatment affect $\sim 10 \%$ of the U.S. population; $\sim 30 \%$ of those with disability suffer from chronic pain (McQuay and Moore, 1998). Furthermore, currently available medications have either limited efficacy or serious side effects. Nevertheless, the neural mechanisms underlying pain processing and potential molecular targets for pharmacotherapy are still incompletely understood. Further research into developing novel pain therapies is needed.

$\alpha$-Lipoic acid (LA) (thioctic acid, oxidized form) and dihydrolipoic acid (DHLA) (dihydrothioctic acid, reduced form) are endogenous, lipid-soluble, sulfur-containing mitochondrial cofactors that are ubiquitous in living organisms, including neurons. LA and DHLA are important in the citric-acid cycle and in energy metabolism; in addition, they function as scavengers of free radicals and participate in redox reactions that modulate sulfhydryl (thiol) groups in various proteins (Smith et al., 2004). Recent studies have shown that LA is an effective analgesic agent in various animals (Cameron et al., 2001; Joseph et al., 2008), including humans (Ziegler et al., 2006; Patton et al., 2007; Memeo and Loiero, 2008). However, the molecular basis for its analgesic

\footnotetext{
Received Dec. 5, 2008; revised May 27, 2009; accepted June 19, 2009.

Our research was supported by Dr. Harold Carron's endowment (to V.J.-T.), National Institutes of Health (NIH) R0-1 Grant GM075229 (to S.M.T.), NIH fellowship F31NS059190 (to P.O.), funds from the Department of Anesthesiology at University of Virginia (UVA) (to V.J.-T. and S.M.T.), and funds from InJe University (W.Y.L.). V.J.-T. is an Established Investigator of the American Heart Association. We thank Dr. Kevin Campbell for providing the initial pair of Cay 3.2 KO mice, Damir Bojadzic for genotyping, and Dr. Wenhao Xu for providing the services of the UVA Gene Targeting and Transgenic Facility.

*W.Y.L. and P.O. contributed equally to this work.

Correspondence should be addressed to Slobodan M. Todorovic, Department of Anesthesiology, University of Virginia Health System, Mail Box 800710, Charlottesville, VA 22908-0710. E-mail: st9d@virginia.edu.

DOI:10.1523/JNEUROSCI.5803-08.2009

Copyright $\odot 2009$ Society for Neuroscience $\quad$ 0270-6474/09/299500-10\$15.00/0
}

effects are poorly understood. In addition, there are no data that link the analgesic effects of LA to specific ion channels that can modulate the excitability of neurons in pain pathways.

Recent molecular and genetic studies have established that T-channels in nociceptors of dorsal root ganglia (DRG) function as signal amplifiers of both acute and chronic pain (Bourinet et al., 2005; Choi et al., 2007), probably because of their profound effects on the excitability of these cells (Nelson et al., 2005, 2007a; Jagodic et al., 2007, 2008). The function of these channels in DRG cells both in vitro and in vivo can be modulated by a variety of redox agents (Todorovic et al., 2001a, 2004; Nelson et al., 2005, 2007a,b; Pathirathna et al., 2006). Hence, we investigated the hypothesis that LA can modulate T-currents in acutely isolated DRG cells and that this modulation contributes to the documented analgesic properties of LA in vivo. We also studied the molecular basis of T-channel modulation by these oxidizing agents.

\section{Materials and Methods}

Acutely isolated DRG neurons

DRG cells from adolescent rats were prepared as previously described (Todorovic and Lingle, 1998; Nelson et al., 2005, 2007a,b). For recording, cells were plated onto uncoated glass coverslips, placed in a culture dish, and perfused with external solution. All in vitro experiments were done at room temperature.

\section{Human embryonic kidney 293 cells}

Human embryonic kidney (HEK) 293 cells were grown in DMEM/F12 medium (Invitrogen) supplemented with fetal calf serum (10\%), penicillin $\mathrm{G}(100 \mathrm{U} / \mathrm{ml})$, and streptomycin $(0.1 \mathrm{mg} / \mathrm{ml})$. To construct the $\mathrm{Ca}_{\mathrm{v}} 3.2$ mutants C939A and $\mathrm{Ca}_{\mathrm{v}} 3.2 \mathrm{Cys}$ (3) (C123A, C128A and C133A), a human $\mathrm{Ca}_{\mathrm{v}} 3.2 \mathrm{cDNA}$ (GenBank accession number AF051946) contained in pcDNA3 was mutated using oligonucleotide primers and the single overlap extension technique. The primers, obtained from Invitrogen, were used without purification. The full-length cDNA of either C939A or 
A DRG
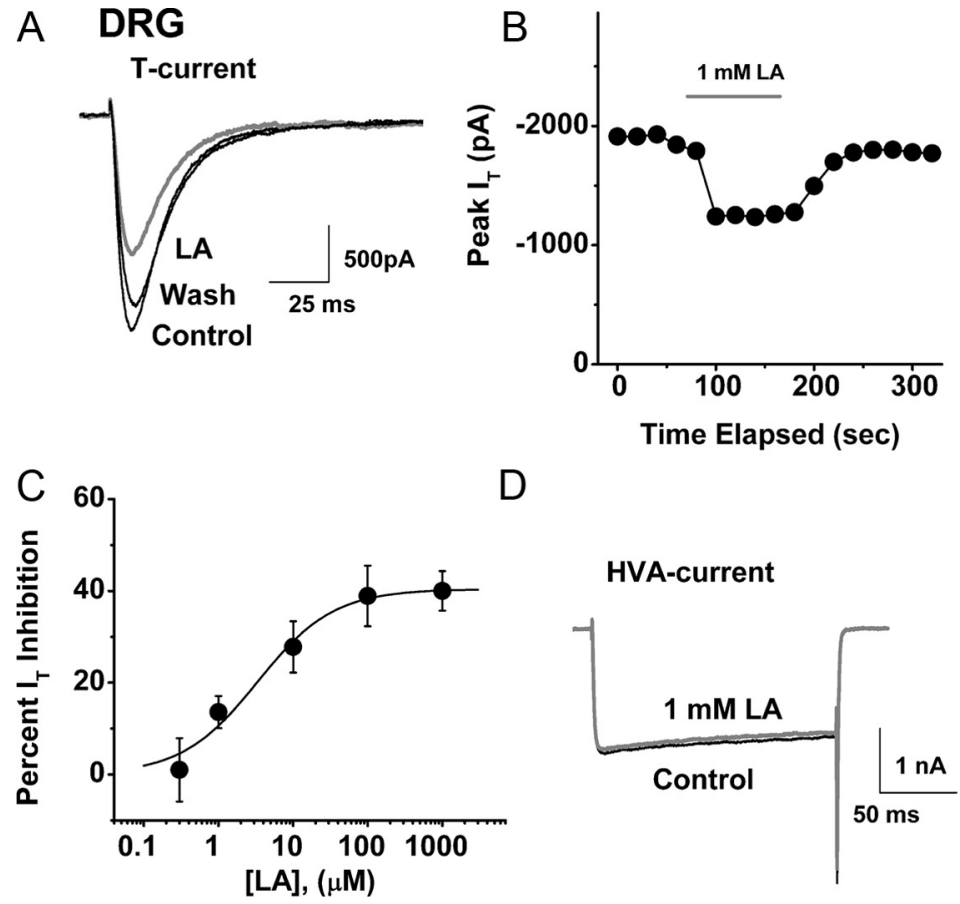

$\mathrm{E}$

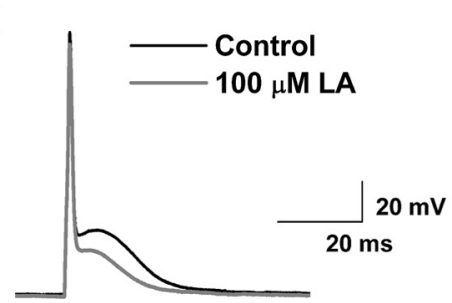

HVA-current

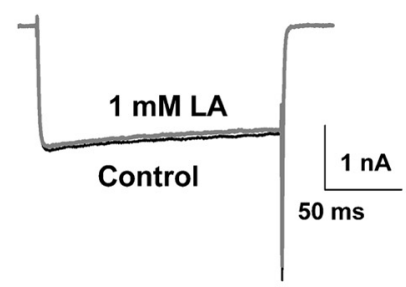

$\mathrm{F}$

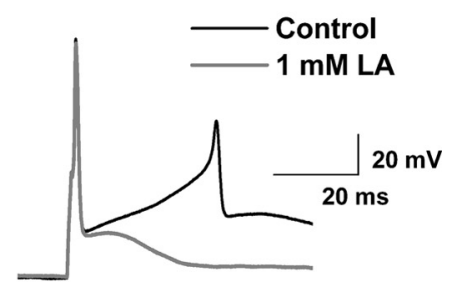

Figure 1. LA selectively inhibits T-type $\mathrm{Ca}^{2+}$ currents and underlying after-depolarizing potentials in acutely dissociated rat sensory neurons. $\boldsymbol{A}$, Traces of T-current in a representative DRG cell before and after (black traces), as well as during bath application of $1 \mathrm{~mm}$ LA (gray trace), which reversibly inhibited $\sim 38 \%$ of peak inward current. Bars indicate calibration. $\boldsymbol{B}$, Temporal record from the same cell presented on panel A of this figure. Gray bar indicates duration of LA application. $C$, Concentration-response relationship for LA inhibition of T-current in rat DRG cells ( $n=6-20$ per data point). Solid line is the best fit (Eq. 1; see Materials and Methods) yielding $\mathrm{IC}_{50}$ of $3.3 \pm 1.5 \mu \mathrm{M}$, slope coefficient $0.8 \pm 0.2$, and maximal inhibition of $40.4 \pm 3.1 \%$ of the peak of T-current. D, Traces of HVA Ca ${ }^{2+}$ current from another DRG cell before (black trace) and during the bath application of $1 \mathrm{~mm} L A$ (gray trace). Bars indicate calibration. $\boldsymbol{E}$, AP waveforms in a representative DRG cell before (black trace) and during application of $100 \mu \mathrm{m}$ LA (gray trace). Note that LA application had little effect on RMP and the initial AP spike, but attenuated the maximal amplitude of ADP by $\sim 30 \%$ and the duration of ADP (measured at half-maximal height) by $\sim 45 \%$. $\boldsymbol{F}$, The same experimental protocol (described in $\boldsymbol{E}$ ) was used in another DRG cell that fired a repetitive APs at the crest of ADP (black traces). When $1 \mathrm{~mm} L A$ was applied in the bath, the initial amplitude of ADP was decreased $\sim 20 \%$ and the cell did not fire repetitively (gray trace) when the same single depolarizing stimulus was injected through the recording electrode.

$\mathrm{Ca}_{\mathrm{v}} 3.2 \mathrm{Cys}$ (3) was reassembled using a HindIII/AgeI fragment. The fulllength cDNA of the $\mathrm{Ca}_{\mathrm{v}} 3.2 \mathrm{Cys}(4)$ mutant $(\mathrm{C} 939 \mathrm{~A}, \mathrm{C} 123 \mathrm{~A}, \mathrm{C} 128 \mathrm{~A}$, and C133A) was constructed by moving an AscI/AscI fragment from $\mathrm{Ca}_{\mathrm{v}} 3$.2Cys(3) into C939A. The sequences corresponding to these fragments were verified by automated sequencing. Cells were transiently cotransfected using Lipofectamine 2000 (Invitrogen) at a 10:1 molar ratio with a plasmid encoding CD8 antigen, then incubated with polystyrene

microbeads coated with anti-CD8 antibody (Invitrogen). After $48 \mathrm{~h}$, cells with bound microbeads were selected for recording.

\section{Electrophysiology}

Recording electrodes were pulled from borosilicate glass microcapillary tubes (Drummond Scientific); when filled with solution, they had resistances between 1 and $4 \mathrm{M} \Omega$. We made recordings using an Axopatch 200B patch-clamp amplifier (Molecular Devices) and Cornerstone PCONE patch-clamp amplifier (Dagan). Digitization of membrane voltages and currents was controlled using a Digidata 1322A interfaced with Clampex 8.2 or 9.0 (Molecular Devices). We analyzed data using Clamp- fit 8.2 or 9.0 (Molecular Devices) and Origin 7.0 (Microcal Software). Currents were lowpass filtered at $2-5 \mathrm{kHz}$. We took series resistance and capacitance values directly from readings of the amplifier after electronic subtraction of the capacitive transients. Series resistance was compensated to the maximum extent possible (usually $50-80 \%$ ). Multiple independently controlled glass syringes served as reservoirs for a gravity-driven perfusion system.

\section{Recording solutions}

The external solution for voltage-clamp experiments in DRG and HEK293 cell experiments contained (in $\mathrm{mM}$ ), 152 tetraethylammonium (TEA) - Cl, 2-10 $\mathrm{BaCl}_{2}$, and 10 HEPES, adjusted to $\mathrm{pH} 7.4$ with TEA-hydroxide $(\mathrm{OH})$. In some experiments with HEK293 cells, external solution contained $5 \mathrm{~mm} \mathrm{CaCl}$ instead $\mathrm{BaCl}_{2}$. The external solution for current-clamp experiments in DRG cell experiments contained (in $\mathrm{mm}$, $140 \mathrm{NaCl}, 4 \mathrm{KCl}, 2 \mathrm{MgCl}_{2}, 2 \mathrm{CaCl}_{2}, 10$ glucose, and 10 HEPES, adjusted to $\mathrm{pH}$ 7.4. To allow studies of well isolated and well clamped T-type currents in acutely isolated DRG cells, we used only fluoride $\left(\mathrm{F}^{-}\right)$-based internal solution to facilitate high voltage-activated (HVA) $\mathrm{Ca}^{2+}$ current rundown (Todorovic and Lingle, 1998); this internal solution for voltage-clamp experiments with DRG neurons contained (in mM) 135 tetramethylammonium-OH, 40 HEPES, 10 EGTA, and $2 \mathrm{MgCl}_{2}$, adjusted to $\mathrm{pH} 7.2$ with hydrogen fluoride (HF). We supplemented

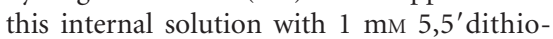
bis-2-nitrobenzoic acid (DTNB) for biophysical studies depicted on Figures 2 and 3. Typically, T-currents are evoked from the holding potential $\left(\mathrm{V}_{\mathrm{h}}\right)$ of $-90 \mathrm{mV}$ and depolarization to test potential $\left(\mathrm{V}_{\mathrm{t}}\right)$ of $-30 \mathrm{mV}$, whereas HVA $\mathrm{Ca}^{2+}$ currents were evoked from $\mathrm{V}_{\mathrm{h}}$ of $-40 \mathrm{mV}$ and depolarization to $\mathrm{V}_{\mathrm{t}}$ of $0 \mathrm{mV}$. The amplitude of the T-current at any given potential was measured from the end of the pulse to its peak. For current-clamp recordings, action potential (AP) was evoked by a single $1 \mathrm{~ms}$ injection of $3 \mathrm{nA}$ depolarizing current through the recording pipette.

The internal solution for voltage-clamp experiments with HEK293 cells contained (in $\mathrm{mm}$ ), 110 Cs- $\mathrm{MeSO}_{4} 14$ creatine phosphate, 10 HEPES, 9 EGTA, 5 Mg-ATP, and 0.3 Tris-GTP, adjusted to $\mathrm{pH} 7.3$ with $\mathrm{CsOH}$. The internal solution for current-clamp experiments with DRG cells contained (in $\mathrm{mm}$ ), $130 \mathrm{KCl}, 40 \mathrm{HEPES}, 5$ $\mathrm{MgCl}_{2}, 2 \mathrm{Mg}$-ATP, 1 EGTA, and $0.1 \mathrm{Na}_{3} \mathrm{GTP}$, adjusted to $\mathrm{pH} 7.3$ with $\mathrm{KOH}$.

All drugs were prepared as stocks and freshly diluted to the final concentrations in the external solution at the time of experiments. LA was prepared as $600 \mathrm{~mm}$ stock in ethanol, $600 \mathrm{~mm}$ DTNB, $300 \mathrm{~mm} 2$ (trimethylammonium) ethyl methanethio sulfonate (MTSET) and $100 \mathrm{~mm} N$-ethylmaleimide (NEM) in DMSO. The final concentrations of ethanol and DMSO had no significant effect on T-current amplitude in DRG and HEK cells (data not shown).

The apparent high affinity of $\mathrm{Ca}_{\mathrm{v}} 3.2$ channels for zinc $\left(\mathrm{Zn}^{2+}\right)$ and the substantial tonic inhibition of these channels by contaminating $\mathrm{Zn}^{2+}$ in our recording solutions necessitated the use of buffered $\mathrm{Zn}^{2+}$ solutions to establish an accurate concentration-response relationship. For these experiments, calibrated free $\mathrm{Zn}^{2+}$ concentrations were obtained using the low-affinity $\mathrm{Zn}^{2+}$ chelator tricine (Paoletti et al., 1997; Nelson et al., 2007a). Nominally " $\mathrm{Zn}^{2+}$-free" reference solutions were made by sub- 
stituting $10 \mathrm{~mm}$ tricine for $10 \mathrm{~mm}$ HEPES in our normal external solution with no additional $\mathrm{Zn}^{2+}$.

\section{Analysis}

Statistical comparisons were made using paired or unpaired $t$ tests or Mann-Whitney $U$ tests where appropriate. All data are expressed as mean \pm SEM; $p$ values are reported only when statistically significant $(<0.05)$. The percentage reductions in peak current at various $\mathrm{LA}$ and $\mathrm{Zn}^{2+}$ concentrations were used to generate concentration-response curves. Mean values were fit to the following Hill-Langmuir function:

$$
\mathrm{PI}([\text { drug }])=\mathrm{PI}_{\max } /\left(1+\left(\mathrm{IC}_{50} /[\text { drug }]\right)^{h}\right),
$$

where $\mathrm{PI}_{\max }$ is the maximal percentage inhibition of peak current by drug, $\mathrm{IC}_{50}$ is the concentration that produces $50 \%$ inhibition, and $h$ is the apparent Hill-Langmuir coefficient for inhibition. The fitted values are reported with $>95 \%$ linear confidence limits. The voltage dependencies of activation and steady-state inactivation were described with single Boltzmann distributions of the following forms:

Activation: $G(V)=G_{\max } /$

$$
\left(1+\exp \left[-\left(V-V_{50}\right) / k\right]\right)
$$

Inactivation: $I(V)=I_{\max } /$

$$
\left(1+\exp \left[\left(V-V_{50}\right) / k\right]\right),
$$

where $I_{\max }$ is the maximal activatable current, $G_{\max }$ is the maximal conductance, $V_{50}$ is the voltage where half the current is activated or inactivated, and $k$ is the voltage dependence (slope) of the distribution.

To study the effects of LA on peak T-channel conductance (see Fig. 2E), values defined as $I_{\text {peak }} /\left(V_{\mathrm{T}}-E_{\mathrm{r}}\right)$ were plotted against command potentials in conditions before and after LA applications in the same cells, calculated from the average current-voltage ( $I-V)$ curve shown in Figure $2 B$. The extrapolated reversal potential $\left(\mathrm{E}_{\mathrm{r}}\right)$ was taken to be $+60 \mathrm{mV}$ and was calculated in cells in which maximal HVA current amplitude was not bigger than 200 pA by running $5 \mathrm{mV}$ incremental depolarizing steps from -80 to $+60 \mathrm{mV}$.

To study T-current deactivation, the cells were held at $-90 \mathrm{mV}$, then subjected to a 14 ms-long activating pulse to $-30 \mathrm{mV}$, followed by $10 \mathrm{mV}$ incremental deactivating steps from -160 to $-60 \mathrm{mV}$ (Fig. $1 F$ ).

To study the effects of LA on steady-state inactivation of T-channels (see Fig. $3 A, B$ ), currents are evoked by test steps to $-30 \mathrm{mV}$ after 3.5 s prepulses to potentials ranging from $-110 \mathrm{mV}$ to $-45 \mathrm{mV}$ in $5 \mathrm{mV}$ increments.

To study the onset of closed-state inactivation in DRG cells (see Fig. $3 C$ ), we used variable duration prepulses at $-85 \mathrm{mV}$ and then evoked T-currents $\left(V_{\mathrm{h}},-90 \mathrm{mV} ; V_{\mathrm{t}},-30 \mathrm{mV}\right)$.

Double-pulse protocol with variable duration was used to measure recovery from inactivation at $-90 \mathrm{mV}$ (see Fig. $3 D$ ) and $-120 \mathrm{mV}$ (see Fig. $3 E$ ) after 500 -ms-long inactivating pulse $\left(V_{\mathrm{h}}-90 \mathrm{mV} ; V_{\mathrm{t}},-30 \mathrm{mV}\right)$.

\section{Behavioral studies}

The $\mathrm{Ca}_{\mathrm{V}} 3.2^{-1-}$ mice were generated as described previously (Chen et al., 2003). The $\mathrm{Ca}_{\mathrm{V}} 3.2^{-1-}$ mutation was maintained in $\mathrm{C} 57 \mathrm{BL} / 6 \mathrm{~J}$ background by repeated back-crossing into each genetic background for $>6$ generations. We generated $\mathrm{Ca}_{\mathrm{v}} 3 \cdot 2^{-1-}$ and wild-type control mice by mating heterozygotes from the $\mathrm{C} 57 \mathrm{BL} / 65 \mathrm{~J} \mathrm{Ca}_{\mathrm{V}} 3.2^{+/-}$background. Mice were maintained in a $12 \mathrm{~h}$ light/dark cycle and given ad libitum access to food and water. Animal care and handling were done according to the guidelines of the Institutional Animal Care and Animal Care and Use Committee of the University of Virginia. Every effort was made to minimize animal suffering and the number of animals used.

Assessment of mechanical sensitivity. The withdrawal response to mechanical stimulation was measured by our standard method using von Frey filaments (Todorovic et al., 2001a; Jagodic et al., 2007). This method was modified from Chaplan et al. (1994) to allow time for effective daily assessment of mechanical sensitivity while minimizing residual behavioral responses from repetitious testing (e.g., learning, habituation). 

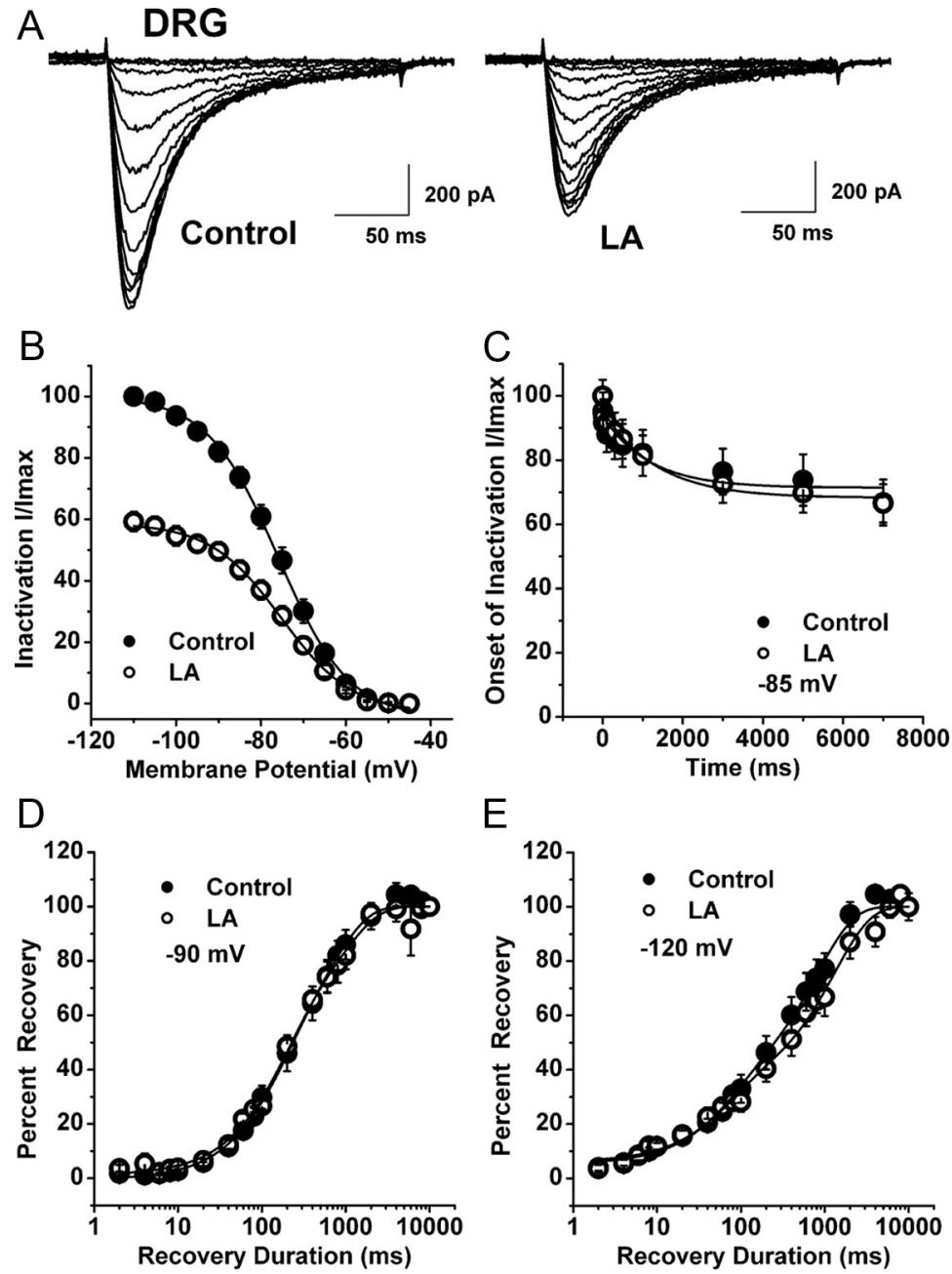

E

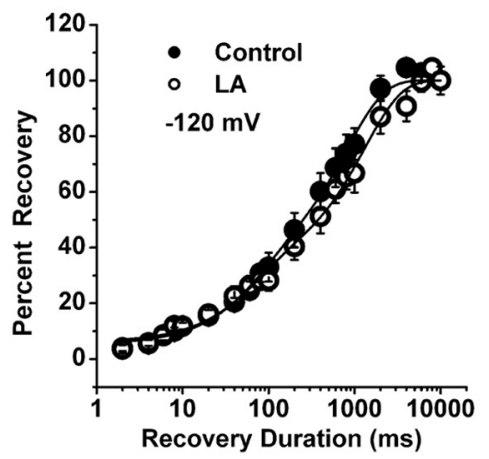

Figure 3. The lack of effect of $L A$ on voltage-dependent inactivation of $T$-current in $D R G$ cells. $A$, Representative original current traces of a small DRG cell in control conditions (left panel) and during bath application of $1 \mathrm{~mm}$ LA (right panel). Calibration bars pertain to both panels. $\boldsymbol{B}$, Normalized peak T-current steady-state inactivation curves from similar experiments shown in the upper panel of this figure ( $n=8$ cells). Filled symbols represent the control conditions; open symbols represent the conditions during bath applications of LA. Solid black lines are fitted using Equation 3 (see Materials and Methods), giving half-maximal availability $\left(V_{50}\right)$, which occurred at $-76.0 \pm 0.5 \mathrm{mV}$ with a $k$ of $8.3 \pm 0.5 \mathrm{mV}$ in control conditions. $V_{50}$ was $-75.2 \pm 0.5 \mathrm{mV}$ with a $k$ of $8.4 \pm$ $0.5 \mathrm{mV}$ in the conditions when LA was applied. C, The graph shows onset of inactivation in DRG cells at $-85 \mathrm{mV}(n=8)$ with filled symbols indicating controls and open symbols indicating applications of $1 \mathrm{~mm}$ LA. Solid lines describe data fit with a single exponential function yielding $\tau$ of $1157 \pm 526 \mathrm{~ms}$ in control and $1323 \pm 298 \mathrm{~ms}$ when LA was applied. D, E, LA has little effects on recovery from inactivation in DRG cells. Symbols indicate averaged data from multiple cells $(n=5)$ that were fitted with a double exponential equation (solid lines): recovery at $-90 \mathrm{mV}(\boldsymbol{D})$ control: $\tau 1,698 \pm 133 \mathrm{~ms} ; \tau 2,151 \pm 38 \mathrm{~ms}$; LA: $\tau 1$, $928 \pm 273 \mathrm{~ms} ; \tau 2,164 \pm 42 \mathrm{~ms}$; recovery at $-120 \mathrm{mV}(\boldsymbol{E})$ control: $\tau 1,817 \pm 87 \mathrm{~ms} ; \tau 2,70 \pm 20 \mathrm{~ms} ; \mathrm{LA}: \tau 1,1299 \pm$ $152 \mathrm{~ms}, \tau 2,66 \pm 20 \mathrm{~ms}$.

Mice were placed in a clear plastic cage with a wire-mesh bottom divided into four compartments, permitting mice freedom of movement while allowing access to their paws. von Frey filaments (Stoelting), which are designated as the $\log _{10}$ (milligram weight required to cause bending $\mathrm{X} 10$ ), were used to assess the mechanical threshold for paw withdrawal. We found that applying the filament \# 2.44 (which are reported by the company to produce $0.04 \mathrm{~g}$ of force) to the plantar surface of the foot causes a noxious response in mice that results in an average of 3-4 paw withdrawal responses (PWRs) in 10 trials. Baseline PWRs were determined in both paws $2 \mathrm{~d}$ before (see Fig. $7 B$, point $\mathrm{B}$ ) and immediately before (see Fig. $7 B$, point 0 ) intradermal administration of either LA or vehicle and then at 10 min thereafter.

Assessment of thermal sensitivity. We used a Hargreaves test (Hargreaves et al., 1988; Jevtovic-Todorovic et al., 1998) with a previously described custom-built plantar test device (Todorovic et al., 2001a, 2004; Pathirathna et al., 2006) adapted for mouse testing, to measure hind-paw thermal sensitivity. During this commonly used test of peripheral nociceptive responses, animals moved freely within an open-topped transparent plastic chamber. Mice were accommodated on the glass floor for $60 \mathrm{~min}$ before testing. A movable radiant heat source was placed under the glass floor and focused on either hindpaw. Paw withdrawal latency (PWL) times were measured with a cutoff time of $15 \mathrm{~s}$ to prevent thermal injury to the skin. Baseline PWLs were determined in both paws $1 \mathrm{~d}$ before and immediately before intradermal administration of either LA or vehicle and then at 10, 20, 40 and 60 min thereafter.

Local intradermal injections. To test the effects of LA, we intradermally injected into the ventral side of the right hindpaw 2 or $1 \mu \mathrm{g}$ of LA (corresponding to the estimated concentrations of $1 \mathrm{~mm}$ and $0.5 \mathrm{~mm}$, respectively) or vehicle in $10 \mu \mathrm{l}$ of saline. Wild-type littermates were used as controls. All solutions were $\mathrm{pH}$ balanced to 7.4 to avoid skin irritation. No signs of skin inflammation, discoloration, or irritation were noted at the sites of injection with test compounds. For behavioral experiments, statistical comparisons were made using two-way repeated ANOVAs followed by Holm-Sidak multiple comparison, with statistical significance accepted if $p<0.05$. All drug injections were performed in a blinded manner.

\section{Results}

DRGs contain somas of small-diameter primary afferent sensory fibers that originate as pain endings in the periphery and terminate in the dorsal horn of the spinal cord. We used whole-cell recordings from acutely dissociated DRG neurons of adolescent rats to study peripheral nociceptive mechanisms, because the small size of peripheral nerve endings precludes direct measurement of currents from sensory endings. We limited our experiments to smaller $(<35 \mu \mathrm{m}$ average diameter $)$ acutely dissociated neurons because the majority of these cells are likely to be involved in nociceptive processing in vivo (Levine et al., 1993; Snider and McMahon, 1998; Caterina and Julius, 2001). To this end, our previous studies have established that most of these cells that express T-currents respond to capsaicin and/or have intense staining with $\mathrm{IB}_{4}$, two principal markers of nociceptive function of DRG cells (Todorovic et al., 2001a; Nelson et al., 2005; Jagodic et al., 2007).

\section{Selective inhibition of T-current by LA in DRG cells}

In an effort to identify endogenous modulators of excitability in sensory neurons, we initially examined whether LA altered voltage-gated $\mathrm{Ca}^{2+}$ currents in these cells. Traces in Figure $1 \mathrm{~A}$ and temporal record in Figure $1 B$ illustrate a representative DRG cell, in which application of $1 \mathrm{~mm}$ LA in external solution reversibly inhibited $\sim 38 \%$ of the peak T-current. The inhibition of T-current induced by brief exposures to LA $(\sim 1-2 \mathrm{~min})$ was largely reversible during washout; there was a nearly complete recovery of baseline current. 
Next, we examined the sensitivity of T-current inhibition by testing several concentrations of LA in different DRG cells. Maximal inhibition of current of $\sim 40 \%$ was achieved by $100 \mu \mathrm{M}$ and $1 \mathrm{mM}$ LA with calculated $\mathrm{IC}_{50}$ of $3 \pm 1 \mu \mathrm{M}$ (Fig. $1 C)$. In contrast, the same maximal concentration of LA had little effect on HVA current recorded in DRG cells (Fig. 1D). On average, $1 \mathrm{~mm}$ LA inhibited $40 \pm 4 \%$ of T-current ( $n=30, p<0.001$, paired $t$ test) but had no significant effect on HVA current ( $1 \pm 3 \%$ change of baseline current, $n=13, p>0.05$, paired $t$ test).

We next tested whether partial inhibition of T-current would be sufficient to diminish T-channel-dependent afterdepolarizing potentials (ADPs) and underlying spike firing in these cells (Nelson et al., 2005; Jagodic et al., 2007). In current-clamp recordings, we found that 0.1-1.0 mM LA inhibited ADPs and underlying repetitive spike firing with minimal effects on resting membrane potential (RMP) or $\mathrm{Na}^{+}$current-mediated APs (Fig. $1 E, F$ ). On average, LA reduced the maximal amplitude of ADP by $23 \pm 6 \%$ $(n=5, p<0.05)$. This is important since changes in the excitability of nociceptive sensory neurons are generally thought to contribute directly to pain sensation in vivo (Campbell and Meyer, 2006).

We then set out to discern the biophysical mechanisms of T-current modulation by LA, which could contribute to the inhibition of current and diminished cellular excitability we observed in currentclamp recordings. To determine the effects of LA on the kinetic properties of DRG T-currents, we measured $I-V$ relationships in the presence and absence of LA (Fig. $2 A, B$ ). We found that LA reduced T-current amplitudes at all potentials between -50 and $-20 \mathrm{mV}$, but had little effect on the kinetics of macroscopic current activation or inactivation (Fig. 2C,D). Interestingly, LA did induce a significant $7 \mathrm{mV}$ rightward shift in half-maximal activation $\left(V_{50}\right)$ with a decrease in voltage dependence having an average $V_{50}$ of $-42.9 \pm 2.4 \mathrm{mV}$ in controls and an average $V_{50}$ of $-35.8 \pm 2.9 \mathrm{mV}$ during LA applications ( $n=6, p<0.05$ by paired $t$ test) (Fig. $2 E$ ). In addition, LA increased the rate of channel closure after repolarization, as shown by faster deactivation $\tau \mathrm{s}$ at $-80,-70$, and $-60 \mathrm{mV}$ (Fig. $2 F)$. In contrast, LA had little effect on aspects of the voltagedependent kinetics of channel inactivation, including steady-state inactivation (Fig. $3 A, B$ ), onset of inactivation (Fig. $3 C$ ), and recovery from inactivation (Fig. 3D,E).

\section{Redox mechanisms of LA modulation of T-channels in DRG cells}

LA is a redox-reactive dithiol compound capable of modulating thiol groups on other proteins in tissues (Smith et al., 2004). Thus, we decided to determine whether irreversible thiol modi-
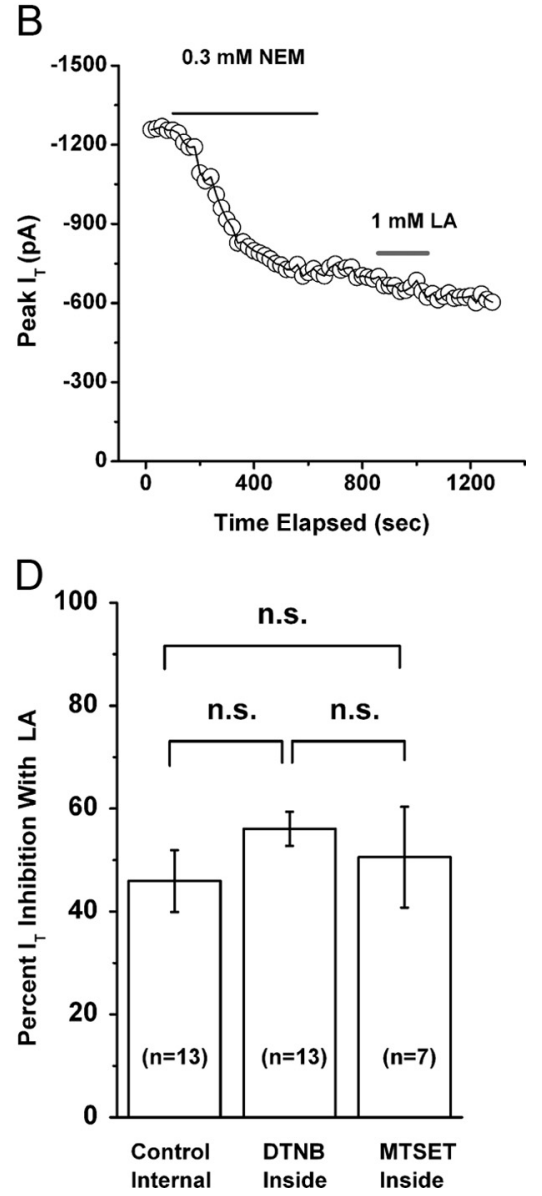

Figure 4. Redox mechanisms of LA inhibition of T-current in DRG cells. $A$, Representative traces show LA (gray trace) inhibition course from the same experiment depicted in panel A of this figure. NEM inhibited $\sim 50 \%$ of the peak baseline T-current. When 1 mM LA was applied after NEM treatment, it induced only a small inhibition ( 10\%) of the remaining inward current. Note that the time of LA application; black horizontal line indicates the time of NEM application. C, Representative traces in gray show (black traces) in different DRG cells. In both experiments, $1 \mathrm{~mm}$ LA was applied in the bath. Top pane

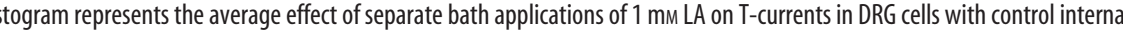
solution (left column), and with internal solution containing either 1 mм DTNB (middle column) or 1 mм MTSET (right column). The average peak T-current inhibition was $46 \pm 6 \%$ in control, $56 \pm 3 \%$ with DTNB, and $51 \pm 10 \%$ with MTSET. Vertical lines are \pm SEM of multiple determinations. Number of cells in each experiment is indicated in parentheses. n.s., Not significant $(p>0.05)$.

fication of T-channels in DRG neurons alters the effects of LA on T-currents. NEM has been commonly used in studies of redox reactions since it covalently modifies protein thiol groups by alkylation and thus may block thiol-based redox reactions on regulatory cysteines in proteins of interest (Stamler et al., 2001). We reasoned that if LA changes a cell's redox states by acting on putative thiol groups on the DRG T-channel, it should be possible to eliminate or greatly attenuate its effect by a previous bath application of NEM. Figure $4, A$ and $B$, shows the traces and time course of a representative experiment in which we first applied $0.3 \mathrm{~mm}$ NEM to the cells for 8-15 min until an apparent steadystate effect was achieved. On its own, NEM at this concentration slowly and apparently irreversibly blocked baseline T-currents by $\sim 50 \%$ ( $52 \pm 6 \%, n=8$ ). Using the same cells, we then applied 1 mM LA after NEM had been washed out, the point being to avoid direct chemical interaction between these agents. The effect of 1 mM LA measured after NEM application was greatly diminished, 

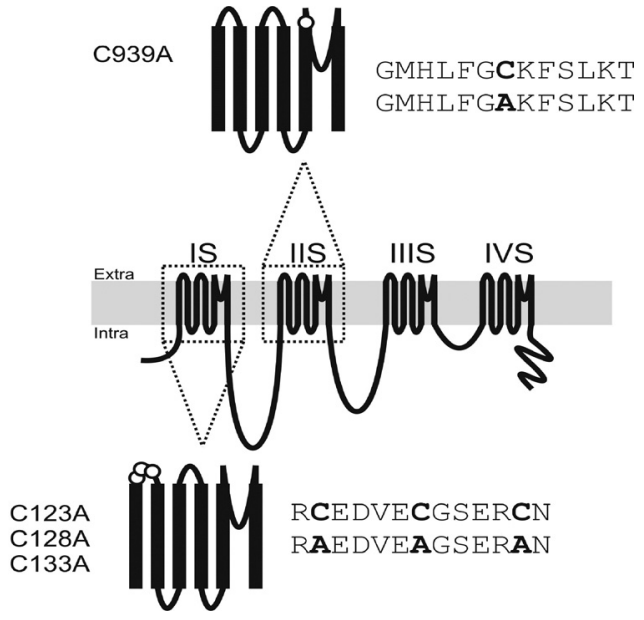

Figure 5. Schematic diagram of $\mathrm{Ca}_{v} 3.2$ showing the position of conserved mutated cysteine residues in the extracellular face of the channel in domains I and II. Designated cysteine residues (in bold) were mutated to alanine residues.

inhibiting only an additional $10 \%$ of T-current. Overall, the effects of $1 \mathrm{~mm}$ LA were significantly attenuated from the control response ( $46 \pm 6 \%$ inhibition, $n=13$ ) when DRG cells were treated with NEM ( $13 \pm 7 \%$ inhibition, $n=8, p<0.01)$. This strongly suggests that the effect of LA on T-current is caused by alterations of thiol groups on channels. However, since both LA and NEM can readily cross the cell membrane, these experiments cannot exclude the possibility that these putative thiol groups are located in the cytoplasm.

To address this issue, we dialyzed acutely dissociated DRG cells with strong membrane-impermeant agents such as $1 \mathrm{~mm}$ DTNB or $1 \mathrm{~mm}$ MTSET, including those in the patch-clamp pipette solution. Representative traces from DRG cells (Fig. 4C) and average histograms from similar experiments (Fig. 4D) indicate that these agents had little effect on LA inhibition of T-current. In control experiments, bath applications of $1 \mathrm{~mm}$ MTSET inhibited $20 \pm 5 \%$ of DRG T-current $(n=5, p<0.01$, data not shown). Similarly, we have previously demonstrated that bath applications of $1 \mathrm{~mm}$ DTNB inhibit $~ 50 \%$ of T-current amplitude in DRG cells (Todorovic et al., 2001a).

\section{Molecular determinants of LA-mediated modulation of $\mathrm{Ca}_{\mathrm{v}} 3.2 \mathrm{~T}$-channels}

The preceding experiments with NEM in native DRG cells strongly suggest that LA inhibits T-current in DRG cells by oxidating thiol (cysteine) groups on the extracellular (cytoplasmic) face of the neuronal membrane. However, $>50$ extracellular cysteine molecules are conserved among T-channel isoforms (PerezReyes, 2003), giving rise to the question of which ones could be critical for LA inhibition of T-current. Cysteine residues are frequently paired and often stabilize structure in proteins by forming covalent disulfide bonds. Therefore, we sought candidate extracellular cysteines that are unique to T-channels versus HVA $\mathrm{Ca}^{2+}$ channels and that are in loops with odd numbers of cysteine molecules. We focused on two regions, repeat II, where there is a single highly conserved cysteine (C939) in the loop connecting S5 to the pore loop, and repeat I, where there are three conserved cysteines in the loop connecting S1 to S2 (C123, C128, C133). Earlier knockdown and knock-out studies have implicated $\mathrm{Ca}_{\mathrm{V}} 3.2$ as the main T-type isoform in smaller DRG cells (Chen et al., 2003; Bourinet et al., 2005; Nelson et al., 2007a). Thus, to begin addressing the molecular basis for LA modulation of T-channels, we assessed the effects of LA on the peak current and kinetic properties of recombinant $\mathrm{Ca}_{\mathrm{V}} 3.2 \mathrm{~T}$-currents in stably transfected HEK 293 cells. The results were much like those we obtained in DRG cells, with LA significantly reducing recombinant $\mathrm{Ca}_{\mathrm{V}} 3.2 \mathrm{~T}$-current amplitudes by $\sim 40 \%$, but having no significant effect on the kinetics of macroscopic current activation or inactivation (Fig. 6A, top panel and bottom left trace). As expected, there was no significant difference in the effects of LA on currents arising from wild-type $\mathrm{Ca}_{\mathrm{V}} 3.1(49.6 \pm 6.5 \%, n=13)$ and wild-type $\mathrm{Ca}_{\mathrm{V}} 3.2$ constructs $(42.1 \pm 3.7 \%, n=20, p>0.05)$ (Fig. 6B, first two bars).

Using $\mathrm{Ca}_{\mathrm{V}} 3.2$ isoform, we performed site-directed mutagenesis of candidate extracellular cysteine residues into alanines, as shown in Figure 5. Then, we tested the effects of $1 \mathrm{~mm}$ LA on mutated $\mathrm{Ca}_{\mathrm{V}} 3.2$, finding that in those containing all four of the critical cysteines mutated together, $\mathrm{Ca}_{\mathrm{v}} 3.2 \mathrm{Cys}(4)$, the inhibitory effect of LA was completely eliminated (120 $\pm 7 \%$ of baseline current, $n=9, p<0.001$ ) (Fig. $6 A$, right bottom trace; Fig. $6 B$, last column). In contrast, mutations of C123A, C128A, and $\mathrm{C} 133 \mathrm{~A}, \mathrm{Ca}_{\mathrm{V}} 3.2 \mathrm{Cys}(3)$, as well as a single mutation of C939A, $\mathrm{Ca}_{\mathrm{V}} 3.2 \mathrm{Cys}(1)$, only partially reduced the inhibitory effect of 1 mu LA on $\mathrm{Ca}_{\mathrm{V}} 3.2$, to $26.5 \pm 6.0 \%(n=13, p<0.05)$ and $28.9 \pm$ $2.9 \%(n=13, p<0.05)$, respectively. Importantly, the $\mathrm{Ca}_{\mathrm{V}} 3.2$ Cys(4) mutation had very small effect on voltage-dependent kinetics of T-channels (supplemental Fig. S1, available at www. jneurosci.org as supplemental material).

We carefully evaluated the possibility that these mutations have nonspecifically altered pharmacological sensitivities of $\mathrm{Ca}_{\mathrm{V}} 3.2$ currents. As shown in the top traces in Figure $6 \mathrm{C}$, the sensitivity of cysteine mutations to other pan-T-channel inhibitors, such as the volatile anesthetic isoflurane (Iso), is similar to that of WT $\mathrm{Ca}_{\mathrm{V}} 3.2$ currents, since in both constructs Iso almost completely inhibited currents. On average, $600 \mu \mathrm{M}$ Iso blocked $80 \pm 3 \%$ T-current in wild-type $\mathrm{Ca}_{\mathrm{V}} 3.2$ channels $(n=9)$ and $75 \pm 4 \%$ in $\mathrm{Ca}_{\mathrm{V}} 3.2$ Cys $(4)$ channels $(n=5, p>0.05)$ (Fig, $6 D$, first two columns). At $100 \mu \mathrm{M}$, dithiothreitol (DTT), a reducing agent with strong metal-chelating properties and a selective $\mathrm{Ca}_{\mathrm{V}} 3.2$ modulator (Todorovic et al., 2001a; Nelson et al., 2007a), similarly increased T-current in both wild-type and the $\mathrm{Ca}_{\mathrm{V}} 3.2$ Cys(4) channel by $\sim 1.5$-fold (Fig. $6 C$, bottom traces). On average, DTT increased baseline peak T-current in $\mathrm{Ca}_{\mathrm{V}} 3.2 \mathrm{Cys}(4)$ constructs to $150 \pm 12 \%(n=3)$ and in wild-type $\mathrm{Ca}_{\mathrm{V}} 3.2$ to $146 \pm 4 \%(n=27, p>0.05)$ (Fig. $6 D$, middle bars of histogram). Furthermore, potent $\mathrm{Zn}^{2+}$ inhibition of the $\mathrm{Ca}_{\mathrm{V}} 3.2 \mathrm{Cys}(4)$ current $\left(\mathrm{IC}_{50} 0.70 \pm 0.07 \mu \mathrm{M}\right)$ indicated that mutations did not alter the high-affinity metal binding site of $\mathrm{Ca}_{\mathrm{V}} 3.2$ (supplemental Fig. S2, available at www.jneurosci.org as supplemental material). However, as predicted, the $\mathrm{Ca}_{\mathrm{V}} 3.2 \mathrm{Cys}(4)$ construct affected the ability of other thiol-modifying oxidizing agents such as DTNB to inhibit T-current. At $1 \mathrm{~mm}$, DTNB inhibited only $28 \pm 4 \%$ of T-current $(n=6)$, which was significantly less than the $56 \pm 3 \%$ of current inhibition in the wild-type $\mathrm{Ca}_{\mathrm{V}} 3.2$ isoform $(n=20$, $p<0.05$ ) (Fig. $6 D$, right side of histogram).

\section{The $\mathrm{Ca}_{\mathrm{V}} 3.2$ channel in peripheral sensory neurons is required for LA modulation of thermal and mechanical hypersensitivity in vivo}

Because LA modulates native and recombinant T-currents in smaller DRG neurons that respond in vitro to noxious heat and capsaicin (Todorovic et al., 2001a, Nelson et al., 2005), we examined whether this agent modifies in vivo sensitivity to noxious thermal (heat) stimuli. In these studies, we injected $10 \mu \mathrm{l}$ of LA directly into 
the peripheral receptive fields of sensory neurons in the hindpaws of adult wild-type $\left(\mathrm{Ca}_{\mathrm{V}} 3.2^{+/+}\right)$and $\mathrm{Ca}_{\mathrm{V}} 3.2$ knock-out $\left(\mathrm{Ca}_{\mathrm{V}} 3.2^{-1-}\right)$ mice, then measured the latency to paw withdrawal in the presence of a radiant heat stimulus (Fig. 7A). As reported previously (Choi et al., 2007) and shown in Figure $7 A, \mathrm{Ca}_{\mathrm{V}} 3.2^{-1-}$ mice have similar baseline thermal sensitivities to their wildtype littermate counterparts. However, intradermal injection of the LA produced a dose-dependent decrease in sensitivity to thermal stimuli only in $\mathrm{Ca}_{\mathrm{V}} 3.2^{+/+}$mice at $10 \mathrm{~min}$ and $20 \mathrm{~min}$ after injection. This was manifested by the transient prolongation of PWLs in injected [right $(\mathrm{R})$ ] paws by $~ 30 \%$ with $2 \mu \mathrm{g} / 10 \mu \mathrm{l}$ and $\sim 12 \%$ with $1 \mu \mathrm{g} / 10 \mu \mathrm{l}$ at $10 \mathrm{~min}$ after injection (Fig. $7 A$, top panel). For example, $2 \mu \mathrm{g} / 10 \mu \mathrm{l}$ LA increased the latency time from the baseline of $5.12 \pm 0.07 \mathrm{~s}$ to $6.76 \pm 0.10 \mathrm{~s}(p<$ $0.001, n=5)$. It is important to note that PWLs in uninjected [left (L)] paws remained stable throughout the testing period, indicating a lack of systemic effect. In control experiments, a higher dose of LA $(2 \mu \mathrm{g} / 10 \mu \mathrm{l})$ had no effect on PWLs in $\mathrm{Ca}_{\mathrm{V}} 3.2^{-1-}$ mice (Fig. $7 A$, middle panel), whereas ethanol $(0.19 \%)$, the vehicle used to dissolve LA, had no effect on PWLs in wildtype littermates (Fig. 7A, lower panel).

The majority of small-size DRG neurons are polymodal nociceptors that respond to a variety of noxious stimuli. Thus, we also studied the effects of intradermal injections of LA on mechanical sensation using von Frey filament \# 2.44 and measuring baseline mechanical PWRs (B), before injections (0 time) and $10 \mathrm{~min}$ after injection. As reported previously (Choi et al., 2007) and shown in Figure $7 B, \mathrm{Ca}_{\mathrm{V}} 3.2^{-1-}$ mice have similar baseline mechanical sensitivities to their wild-type littermate counterparts. However, we found that similar to the effects on thermal sensitivity, locally injected LA induced dose-dependent decrease in mechanical sensitivity at $10 \mathrm{~min}$ after injections only in $\mathrm{Ca}_{\mathrm{v}} 3.2^{+/+}$mice. For example, after injections of $2 \mu \mathrm{g} / 10 \mu \mathrm{l}$ LA into $\mathrm{R}$ paws, PWRs decreased by $47 \%$, and injections of $1 \mu \mathrm{g} / 10 \mu \mathrm{l}$ LA decreased PWRs by $28 \%$ (Fig. $7 B$, top panel). Note that PWRs in uninjected (L) paws remained stable throughout the testing period, indicating a lack of systemic effect. In control experiments, a higher dose of LA $(2 \mu \mathrm{g} / 10 \mu \mathrm{l})$ had no effect on PWRs in $\mathrm{Ca}_{\mathrm{V}} 3.2^{-/-}$mice (Fig. $7 B$, middle panel), whereas ethanol (0.19\%), the vehicle used to dissolve LA, had no effect on PWRs in wild-type littermates (Fig. $7 B$, lower panel). These data indicate that $\mathrm{Ca}_{\mathrm{V}} 3.2$ channels in peripheral sensory neurons are required for LA modulation of mechanical and thermal sensitivity in vivo.
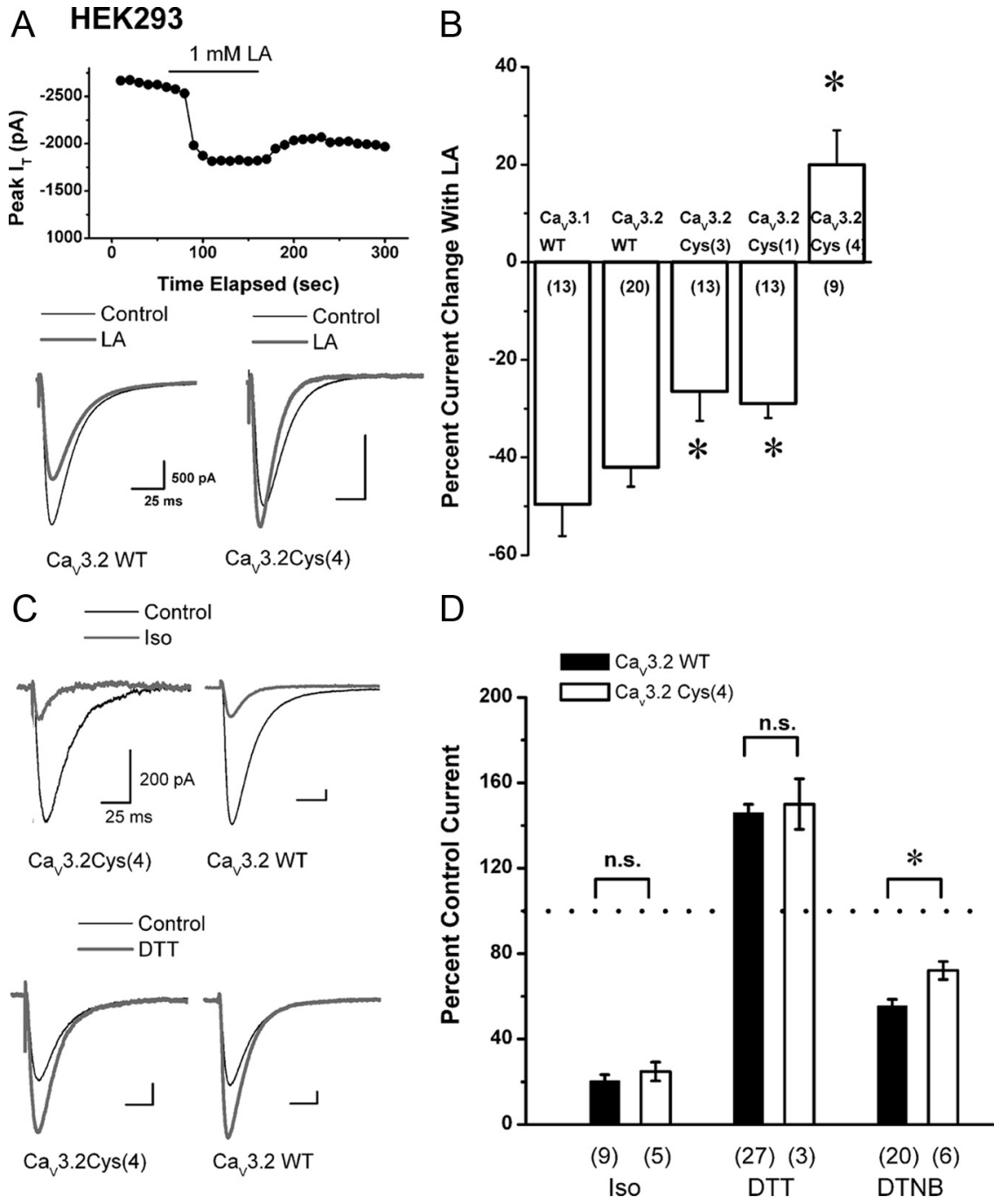

Figure 6. Molecular determinants of inhibition of recombinant $\mathrm{Ca}_{\mathrm{V}} 3.2$ by LA. $\boldsymbol{A}$, Top panel shows the time course of the inhibition ( $\sim 33 \%$ ) of recombinant $C a_{v} 3.2$ currents by $1 \mathrm{~mm} L A$ with partial recovery of peak current amplitude after LA washout. Traces on the bottom show the effect of $1 \mathrm{~mm}$ LA (gray) on control baseline T-currents (black) in a representative HEK 293 cell expressing wild-type (WT) Cav 3.2 (left, same cell as $\boldsymbol{A}$ ) and in a representative HEK cell expressing a mutated channel in which all 4 cysteines were replaced with alanines designated as $\mathrm{Ca}_{\mathrm{v}} 3.2 \mathrm{Cys}(4)$ (right). Note that LA inhibited recombinant $\mathrm{Ca}_{\mathrm{v}} 3.2$ currents in HEK cells in much the same manner as that observed with native T-current in DRG cells, with minimal effect on current kinetics. In contrast, in the Cav3.2Cys(4) mutant LA induced an increase of $\sim 16 \%$ in the amplitude of the peak T-current and accelerated macroscopic current inactivation. Calibration bars pertain to both panels. $\boldsymbol{B}$, Histogram summarizes the average effect of $1 \mathrm{~mm} L A$ in WT Ca $\mathrm{a}_{\mathrm{v}} 3.1$, WT $\mathrm{Ca}_{\mathrm{v}} 3.2$, and $\mathrm{Ca}_{\mathrm{v}} 3.2$ constructs with designated mutations of critical cysteine residues. On average, LA inhibited $50 \pm 7 \%$ of $C a_{v} 3.1$ current and $42 \pm 4 \%$ of $C a_{v} 3.2$ current $(p>0.05)$. Mutants of $C a_{v} 3.2$ with either a three-cysteine, $C a_{v} 3.2 C y s(3)$, or a single cysteine, $\mathrm{Ca}_{\mathrm{V}} 3.2 \mathrm{Cys}(1)$, displayed reduced sensitivity to $L A$ inhibition, with average inhibitions of current of $26.5 \pm 6.0 \%$ and $28.9 \pm 3.0 \%$, respectively. In contrast, bath application of $L A$ in the $C a_{v} 3.2 \mathrm{Cys}(4)$ mutant potentiated current by an average of $20 \pm 7 \%$. The number of cells in each experiment is indicated in parentheses. * indicates a statistically significant difference from Ca 3.2 WT ( $p<$ 0.05). C, Representative traces depict HEK 293 cells expressing either Ca 3.2 Cys (4) mutants (left) or Cay 3.2WT constructs (right) in control conditions (black traces) and during application of $600 \mu \mathrm{m} \mathrm{Iso} \mathrm{(gray} \mathrm{traces,} \mathrm{top)} \mathrm{or} 100 \mu \mathrm{m} \mathrm{DTT} \mathrm{(gray} \mathrm{traces,} \mathrm{bottom).} \mathrm{Note} \mathrm{that} \mathrm{Iso} \mathrm{inhibited}$ $\sim 80 \%$ of the peak T-current in both experiments, whereas DTT enhanced the amplitude of T-current for $\sim 60 \%$ in both experiments. Calibration bars pertain to all four panels. $\boldsymbol{D}$, Histogram summarizes the average effects of Iso, DTT, and DTNB on constructs expressing either $\mathrm{Ca}_{\mathrm{v}} 3.2 \mathrm{WT}$ (solid black columns) or $\mathrm{Ca}_{\mathrm{v}} 3.2 \mathrm{Cys}$ (4) mutants (open columns). During bath applications of Iso, the T-current amplitude was reduced to $25 \pm 4 \%$ and $20 \pm 3 \%$ in $\mathrm{Ca}_{\mathrm{v}} 3.2 \mathrm{Cys}(4)$ and $\mathrm{Ca}_{\mathrm{v}} 3.2 \mathrm{WT}$, respectively. In the presence of DTT in the bath, the current of WT channels are potentiated to $146 \pm 4 \%$ and, in the $\mathrm{Ca}_{\mathrm{v}} 3.2 \mathrm{Cys}(4)$ mutant, to $150 \pm 12 \%$ of the baseline values. In the presence of bath-applied DTNB, the current of WT channels were inhibited t $55 \pm 3 \%$ and, in Ca 3.2 Cys(4) mutants, to $72 \pm 4 \%$ of the baseline values of the peak T-current amplitude. Dotted line indicates baseline T-current amplitude. Vertical lines are \pm SEM; n.S., not significant; ${ }^{*} p<$ 0.05. The number of cells in each experiment is indicated in parentheses.

\section{Discussion}

Although the biophysical properties of T-channels were first described in sensory neurons (Carbone and Lux, 1984), their function in nociception has only recently been established 
A Thermal

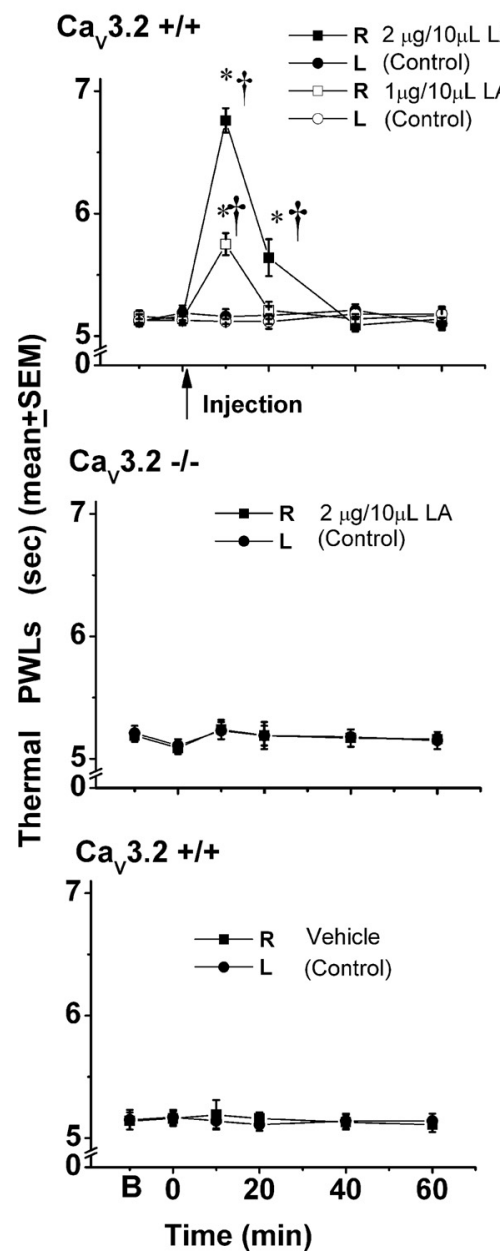

B Mechanical

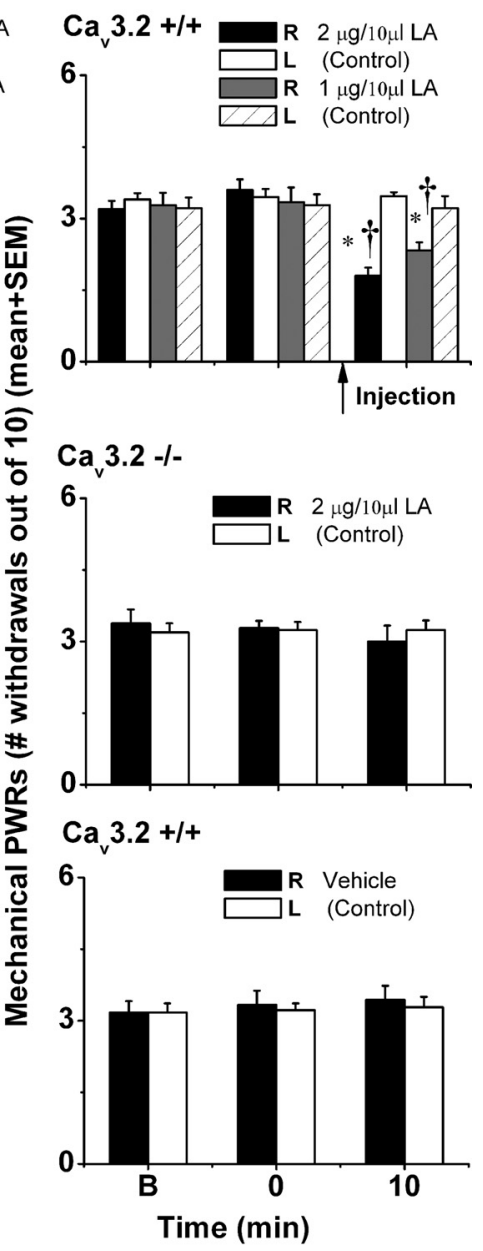

Figure 7. Intraplantar injections of $L A$ in vivo decreased sensitivity to noxious thermal $(\boldsymbol{A})$ and mechanical $(\boldsymbol{B})$ stimuli in wild-type but not $\mathrm{Ca}_{\mathrm{v}} 3.2 \mathrm{KO}$ mice. $\boldsymbol{A}$, The top panel indicates that LA at $1 \mu \mathrm{g} / 10 \mu \mathrm{l}($ solid square symbols, $n=6)$ and $2 \mu \mathrm{g} / 10 \mu \mathrm{l}$ (open square symbols, $n=5$ ) at 10 min after injection in the right paws of $\mathrm{Ca}_{\mathrm{v}} 3.2^{+/+}$littermates increased average thermal (PWLs) (in seconds) from control (left, uninjected paws, round symbols) from $\sim 5.1$ to 5.7 and $6.8 \mathrm{~s}$, respectively. Note that the effect is transient; PWLs returned to baseline levels at 40 and 60 min after intraplantar applications of $L A$. The middle panel shows the lack of effect of LA on the thermal sensitivity of $\mathrm{Ca}_{\mathrm{v}} 3.2^{-1-}$ mice when injected into hindpaws at a dose of $2 \mu \mathrm{g} / 10 \mu \mathrm{l}(n=$ 6). The bottom panel shows the lack of effect of $0.19 \%$ ethanol injections $(n=5)$ on thermal PWLs in $\mathrm{Ca}_{\mathrm{v}} 3.2^{+/+}$mice. As in the middle panel, PWLs remained stable in both right (injected paws, square symbols) and left (uninjected paws, round symbols) throughout testing. Solid arrow indicates times of injection in all three panels. ${ }^{*}$ indicates $p<0.001$ for right versus left paw; $†$ indicates $p<0.001$ for pretreatment versus posttreatment at 10 and $20 \mathrm{~min}$. $\boldsymbol{B}$, The top panel indicates that LA at $1 \mu \mathrm{g} / 10 \mu \mathrm{l}$ (gray filled column, $n=6$ ) and $2 \mu \mathrm{g} / 10 \mu \mathrm{l}$ (black filled column, $n=5$ ) at $10 \mathrm{~min}$ after injection in the right paws of $\mathrm{Ca}_{\mathrm{v}} 3.2^{+/+}$ littermates decreased average mechanical PWRs from control (left, uninjected paws, open columns) by $\sim 28 \%$ and $48 \%$, respec tively. The middle panel shows the lack of effect of $L A$ on the mechanical sensitivity of $\mathrm{Ca}_{\mathrm{v}} 3.2^{-1-}$ mice when injected into hindpaws at a dose of $2 \mu \mathrm{g} / 10 \mu \mathrm{l}(n=6)$. The bottom panel shows the lack of effect of $0.19 \%$ ethanol injections $(n=6)$ on mechanical PWRs in $\mathrm{Ca}_{\mathrm{v}} 3.2^{+/+}$mice. As in the middle panel, PWRs remained stable in both right (injected paws, black filled columns) and left (uninjected paws, open columns) throughout testing. Solid arrow indicates times of injection in all three panels. * indicates $p<0.001$ for right versus left paw; $†$ indicates $p<0.05$ for pretreatment (Band $0 \mathrm{~min}$ ) versus posttreatment at $10 \mathrm{~min}$.

(Todorovic et al., 2001a; Bourinet et al., 2005; Choi et al., 2007). Indeed, the molecular mechanisms that regulate the function of these channels in pain processing still are not well understood. The major finding of this study is that LA inhibits native and recombinant $\mathrm{T}$-currents by oxidizing specific thiol residues on the extracellular face of the channel. Inhibition of $\mathrm{Ca}_{\mathrm{V}} 3.2 \mathrm{~T}$-channels and the ensuing decrease in cellular excitability in nociceptive DRG cells may contribute to the documented analgesic properties of LA in vivo. This notion is strongly supported by the finding that local intraplantar injection of LA potently diminished responses to noxious thermal and mechanical stimuli in wild-type mice, but was completely ineffective in $\mathrm{Ca}_{\mathrm{V}} 3.2$ knock-out mice. Importantly, we identified a novel regulatory site on T-channels in peripheral sensory neurons that may serve in further pharmacological development of pain therapies.

LA is a ubiquitous molecule and mitochondrial cofactor that can act as both anti-oxidant and pro-oxidant, as well as a chelator of transition metals (Moini et al., 2002; Smith et al., 2004). We have recently identified a unique histidine residue $(\mathrm{H} 191)$ of repeat $\mathrm{I}$ of $\mathrm{Ca}_{\mathrm{V}} 3.2$ that forms a molecular basis for subtypespecific redox modulation of $\mathrm{T}$-channels using endogenous substances such as L-cysteine. We also found that L-cysteine increased native DRG T-current amplitude and neuronal excitability in vitro and induced thermal hypersensitivity in vivo by chelating trace metal ions such as $\mathrm{Zn}^{2+}$ (Nelson et al., 2007a). Furthermore, the same critical $\mathrm{H} 191$ residue of $\mathrm{Ca}_{\mathrm{V}} 3.2$ can undergo metal-catalyzed oxidation with ascorbate in the presence of trace metals such as $\mathrm{Cu}^{2+}$, which in turn decreased T-current amplitude and neuronal excitability (Nelson et al., 2007b). Here, we have continued by demonstrating that another endogenous redox-reactive compound, LA, not only had a prominent inhibitory effect on T-currents in vitro, but, importantly, potently diminished sensitivity to noxious thermal and mechanical stimuli in vivo. However, unlike L-cysteine and ascorbic acid, LA similarly affected $\mathrm{Ca}_{\mathrm{V}} 3.1$ and $\mathrm{Ca}_{\mathrm{V}} 3.2$ currents, a finding which indicates that H191 is not required for the inhibition of T-current by LA. Furthermore, our findings strongly suggest that the major effect of LA on T-currents occurs via oxidation of specific extracellular thiol groups in repeats I and II of the channels. This may lead to conformational changes in channel structure, which then may inhibit channel gating and consequently result in decreased $\mathrm{Ca}^{2+}$ entry into the cell, decreased cellular excitability of nociceptors, and decreased pain transmission. It is interesting that LA only partially inhibited T-current, up to $40 \%$. It is possible that full inhibition of the repeats I and II of the channel by LA might show as partial inhibition of the whole current. Similarly, we reported that some other agents like ascorbic acid (Nelson et. all, 2007b), $5 \alpha$-reduced neuroactive steroids (Todorovic et al., 1998), anticonvulsants such as phenytoin and $\alpha$-methyl- $\alpha$-phenyl-succinimide (Todorovic et al., 2000), and anesthetic nitrous oxide (Todorovic et al., 2001b) also partially inhibit DRG T-current. Although the precise mechanism underlying the partial blockade produced by any compound of DRG T-current remains unknown, our data presented herein and previously (Nelson et al., 2005) are consistent with the idea that even 
partial inhibition of T-currents in DRG cells is sufficient to diminish cellular excitability.

We present several findings indicating that LA functions by oxidizing extracellular cysteines on native and recombinant T-channels. First, the effects of LA on native DRG currents were attenuated by the thiol-specific alkylating agent NEM. Second, the effect of LA on DRG T-current was not altered by intracellular applications of strong membrane-impermeant agents such as DTNB and MTSET, which mimicked the effects of LA when applied in the bath. Third, site-directed mutations of 4 critical cysteine residues of recombinant $\mathrm{Ca}_{\mathrm{V}} 3.2$ completely abolished the inhibitory effect of LA on T-current. Importantly, these mutants do not alter the ability of other traditional blocker of T-channels like Iso to inhibit current; similarly, the effects of agents interacting with critical histidine residue (H191) of $\mathrm{Ca}_{\mathrm{V}} 3.2$, such as DTT and $\mathrm{Zn}^{2+}$ apparently are spared. These results argue that mutations of critical cysteine residues had no nonspecific affect on the responses of LA because of changes in channel-gating behavior. The small potentiation of T-current with LA that we observed in this mutant likely resulted from chelation of trace metal ions that exert tonic inhibition of $\mathrm{Ca}_{\mathrm{V}} 3.2$ (Nelson et al., 2007a). This is supported by the likelihood that LA functions as a chelator of trace metals (Smith et al., 2004) and by the fact that LA speeded macroscopic current kinetics in $\mathrm{Ca}_{\mathrm{V}} 3.2 \mathrm{Cys}(4)$ mutants (Fig. 6A), as we reported previously for other chelating agents in $\mathrm{Ca}_{\mathrm{V}} 3.2$ recombinant and native DRG currents (Todorovic et al., 2001a; Nelson et al., 2007a).

It is interesting to note that mutations of these cysteines only partially inhibited the response to DTNB, a traditional thioloxidizing agent. This strongly suggests that DTNB and LA have somewhat different molecular mechanisms of T-channel inhibition. Supporting this possibility are the findings that DTNB more completely inhibits recombinant and native T-currents (Todorovic et al., 2001a; Joksovic et al., 2006) and induces voltagedependent modulation of channel inactivation (Joksovic et al., 2006). In contrast, we report here that LA only partially inhibited T-channels, having a minimal effect on voltage-dependent inactivation, but had a significant effect on channel gating. Additional molecular studies will be needed to identify other critical cysteine residues on $\mathrm{T}$-channels that are modulated by various thioloxidizing agents.

We noted that the inhibitory effect of LA on DRG T-current in vitro generally is spontaneously reversible after short applications of drug. Similarly, we have demonstrated that in vivo applications of LA to peripheral receptive fields of sensory neurons resulted in transient decreases in thermal sensitivity. Since oxidization of thiol groups on protein occurs via relatively stable disulfide bonds, the reversibility of effects strongly suggests that an unknown endogenous reducing factor could be associated with T-channels. However, the putative proteins associated with the pore-forming $\alpha 1$ subunit of T-channels have not yet been identified.

Others have also observed reversible thiol modifications of other proteins with LA (Slepneva et al., 1995). Such reversible redox reactions are proposed to form a basis for homeostatic or physiological reactions or responses of the organism to stress, whereas other irreversible redox modifications of cysteines may ultimately lead to permanent tissue injury (Forrester and Stamler, 2007). Thus, it is unlikely that LA-induced modulation of $\mathrm{T}$-channels in peripheral nociceptors would have a deleterious effect on tissue. However, it is certainly true that T-channels are expressed in many areas of the nervous system, and that critical cysteine molecules that can be oxidized by LA are highly con- served in all isoforms across different species (Perez-Reyes, 2003). Is it therefore possible that LA inhibition of T-channels in CNS have a function in the central modulation of pain transmission and other physiological functions? This appears likely based on the fact that peak plasma levels of LA after its systemic administration to humans range from 5 to $50 \mu \mathrm{M}$ (Hermann et al., 1998; Gleiter et al., 1999). Moreover, we found that LA at these concentrations inhibits $\sim 25-35 \%$ of DRG T-current. However, LA has a reasonably established record of safe use in human pain medicine, and therapeutic levels are associated with few side effects compared with other available pain therapies (Moini et al., 2002; Smith et al., 2004; Ruessmann, 2009).

An earlier in vitro study reported that LA at millimolar concentrations may modulate NMDA-currents in cultured cortical neurons (Tang and Aizenman, 1993). It is unlikely that these effects contribute to the in vivo effect of LA on pain perception that we report here, since NMDA channels do not contribute significantly to peripheral nociception under physiological conditions (Todorovic et al., 2001a). However, it is possible that the inhibitory effect of LA on NMDA currents in CNS could work in concert with inhibition of T-currents in DRG neurons to ameliorate neuropathic pain. We found that although the effect is rather transient, LA is effective in suppressing paw withdrawals to noxious thermal and mechanical stimuli, tests that usually are indicative of peripheral analgesic potency. Longer duration of analgesia could be achieved in humans by using slow-release creams, which could be beneficial in treating conditions where thermal hyperalgesia is prominent (e.g., sunburns). Most peripheral nociceptors are polymodal and the $\mathrm{Ca}_{\mathrm{V}} 3.2$ knock-out mouse has markedly decreased pain responses to acute heat, mechanical, and chemical (formalin, capsaicin) stimuli (Choi et al., 2007). In addition, peripheral $\mathrm{T}$-channels are implicated in chronic neuropathic pain in disorders such as mechanical nerve injury (Todorovic et al., 2004; Bourinet et al., 2005; Jagodic et al., 2008) as well as diabetic neuropathy (Jagodic et al., 2007). Thus, locally applied LA and related endogenous oxidizing agents acting on $\mathrm{Ca}_{\mathrm{V}} 3.2$ $\mathrm{T}$-channels in peripheral nociceptors may decrease peripheral sensitization that ultimately leads to the development of chronic neuropathic pain.

Overall, the results presented here advance our understanding of the redox mechanisms underlying the posttranslational modification of T-channels that has an important function in suppressing peripheral nociceptive signaling. Our results also suggest that the manipulation of redox states of peripheral nociceptors with naturally occurring substances such as LA could be useful for the development of novel therapies for the treatment of pain.

\section{References}

Bourinet E, Alloui A, Monteil A, Barrère C, Couette B, Poirot O, Pages A, McRory J, Snutch TP, Eschalier A, Nargeot J (2005) Silencing of the $\mathrm{Ca}_{\mathrm{V}} 3.2 \mathrm{~T}$-type calcium channel gene in sensory neurons demonstrates its major role in nociception. EMBO J 24:315-324.

Cameron NE, Jack AM, Cotter MA (2001) Effect of alpha-lipoic acid on vascular responses and nociception in diabetic rats. Free Radic Biol Med 31:125-135.

Campbell JN, Meyer RA (2006) Mechanisms of neuropathic pain. Neuron 52:77-92.

Carbone E, Lux HD (1984) A low-voltage activated, fully inactivating Ca2+ channel in vertebrate sensory neurons. Nature 310:501-502.

Caterina MJ, Julius D (2001) The vanilloid receptor: a molecular gateway to the pain pathway. Annu Rev Neurosci 24:487-517.

Chaplan SR, Bach FW, Pogrel JW, Chung JM, Yaksh TL (1994) Quantitative assessment of tactile allodynia in the rat paw. J Neurosci Methods 53:55-63.

Chen CC, Lamping KG, Nuno DW, Barresi R, Prouty SJ, Lavoie JL, Cribbs LL, 
England SK, Sigmund CD, Weiss RM, Williamson RA, Hill JA, Campbell KP (2003) Abnormal coronary function in mice deficient in alpha1H T-type Ca2+ channels. Science 302:1416-1418.

Choi S, Na HS, Kim J, Lee J, Lee S, Kim D, Park J, Chen CC, Campbell KP, Shin HS (2007) Attenuated pain responses in mice lacking $\mathrm{Ca}(\mathrm{V}) 3.2$ T-type channels. Genes Brain Behav 6:425-431.

Forrester MT, Stamler JS (2007) A classification scheme for redox-based modifications of proteins. Am J Respir Cell Mol Biol 36:135-137.

Gleiter CH, Schreeb KH, Freudenthaler S, Thomas M, Elze M, FiegerBüschges H, Potthast H, Schneider E, Schug BS, Blume HH, Hermann R (1999) Lack of interaction between thioctic acid, glibenclamide and acarbose. Br J Clin Pharmacol 48:819-825.

Hargreaves K, Dubner R, Brown F, Flores C, Joris J (1988) A new and sensitive method for measuring thermal nociception in cutaneous hyperalgesia. Pain 32:77-88.

Hermann R, Wildgrube HJ, Ruus P, Niebch G, Nowak H, Gleiter CH (1998) Gastric emptying in patients with insulin dependent diabetes mellitus and bioavailability of thioctic acid-enantiomers. Eur J Pharm Sci 6:27-37.

Jagodic MM, Pathirathna S, Nelson MT, Mancuso S, Joksovic PM, Rosenberg ER, Bayliss DA, Jevtovic-Todorovic V, Todorovic SM (2007) Cellspecific alterations of T-type calcium current in painful diabetic neuropathy enhance excitability of sensory neurons. J Neurosci 27:3305-3316.

Jagodic MM, Pathirathna S, Joksovic PM, Lee W, Nelson MT, Naik AK, Su P, Jevtovic-Todorovic V, Todorovic SM (2008) Up-regulation of the T-type $\mathrm{Ca}^{2+}$ current in small rat sensory neurons after chronic constrictive injury of the sciatic nerve. J Neurophysiol 99:3151-3156.

Jevtovic-Todorovic V, Wozniak DF, Powell S, Nardi A, Olney JW (1998) Clonidine potentiates the neuropathic pain-relieving action of MK-801 while preventing its neurotoxic and hyperactivity side effects. Brain Res 781:202-211.

Joksovic PM, Nelson MT, Jevtovic-Todorovic V, Patel MK, Perez-Reyes E, Campbell KP, Chen CC, Todorovic SM (2006) $\mathrm{Ca}_{\mathrm{V}} 3.2$ is the major molecular substrate for redox regulation of T-type $\mathrm{Ca}^{2+}$ channels in the rat and mouse thalamus. J Physiol 574:415-430.

Joseph EK, Chen X, Bogen O, Levine JD (2008) Oxaliplatin acts on IB4positive nociceptors to induce an oxidative stress-dependent acute painful peripheral neuropathy. J Pain 9:463-472.

Levine JD, Fields HL, Basbaum AI (1993) Peptides and the primary afferent nociceptor. J Neurosci 13:2273-2286.

McQuay H, Moore A (1998) Introduction. In: An evidence-based resource for pain relief (Mcquay H, Moore A, eds), pp 23. Oxford: Oxford UP.

Memeo A, Loiero M (2008) Thioctic Acid and acetyl-L-carnitine in the treatment of sciatic pain caused by a herniated disc: a randomized, double-blind, comparative study. Clin Drug Investig 28:495-500.

Moini H, Packer L, Saris NE (2002) Antioxidant and prooxidant activities of alpha-lipoic acid and dihydrolipoic acid. Toxicol Appl Pharmacol 182:84-90.

Nelson MT, Joksovic PM, Perez-Reyes E, Todorovic SM (2005) The endogenous redox agent $\mathrm{L}$-cysteine induces T-type $\mathrm{Ca}^{2+}$ channel-dependent sensitization of a novel subpopulation of rat peripheral nociceptors. J Neurosci 25:8766-8775.

Nelson MT, Woo J, Kang HW, Vitko I, Barrett PQ, Perez-Reyes E, Lee JH, Shin HS, Todorovic SM (2007a) Reducing agents sensitize C-type nociceptors by relieving high-affinity zinc inhibition of T-type calcium channels. J Neurosci 27:8250-8260.

Nelson MT, Joksovic PM, Su P, Kang HW, Van Deusen A, Baumgart JP, David LS, Snutch TP, Barrett PQ, Lee JH, Zorumski CF, Perez-Reyes E,
Todorovic SM (2007b) Molecular mechanisms of subtype-specific inhibition of neuronal T-type calcium channels by ascorbate. J Neurosci 27:12577-12583.

Paoletti P, Ascher P, Neyton J (1997) High-affinity zinc inhibition of NMDA NR1-NR2A receptors. J Neurosci 17:5711-5725.

Pathirathna S, Covey DF, Todorovic SM, Jevtovic-Todorovic V (2006) Differential effects of endogenous cysteine analogs on peripheral thermal nociception in intact rats. Pain 125:53-64.

Patton LL, Siegel MA, Benoliel R, De Laat A (2007) Management of burning mouth syndrome: systematic review and management recommendations. Oral Surg Oral Med Oral Pathol Oral Radiol Endod 103 [Suppl]: S39.el-e13.

Perez-Reyes E (2003) Molecular physiology of low-voltage-activated T-type calcium channels. Physiol Rev 83:117-161.

Ruessmann HJ, German Society of Out Patient Diabetes Centres AND (Arbeitsgemeinschaft niedergelassener diabetologisch tätiger Ärzte e.V.) (2009) Switching from pathogenetic treatment with alpha-lipoic acid to gabapentin and other analgesics in painful diabetic neuropathy: a realworld study in outpatients. J Diabetes Complications 23:174-177.

Slepneva IA, Sergeeva SV, Khramtsov VV (1995) Reversible inhibition of NADPH-cytochrome P450 reductase by alpha-lipoic acid. Biochem Biophys Res Commun 214:1246-1253.

Smith AR, Shenvi SV, Widlansky M, Suh JH, Hagen TM (2004) Lipoic acid as a potential therapy for chronic diseases associated with oxidative stress. Curr Med Chem 11:1135-1146.

Snider WD, McMahon SB (1998) Tackling pain at the source: new ideas about nociceptors. Neuron 20:629-632.

Stamler JS, Lamas S, Fang FC (2001) Nitrosylation: the prototypic redoxbased signaling mechanism. Cell 106:675-683.

Tang LH, Aizenman E (1993) Allosteric modulation of the NMDA receptor by dihydrolipoic and lipoic acid in rat cortical neurons in vitro. Neuron 11:857-863.

Todorovic SM, Lingle CJ (1998) Pharmacological properties of T-type $\mathrm{Ca}^{2+}$ current in adult rat sensory neurons: effects of anticonvulsant and anesthetic agents. J Neurophysiol 79:240-252.

Todorovic SM, Prakriya M, Nakashima YM, Nilsson KR, Han M, Zorumski CF, Covey DF, Lingle CJ (1998) Enantioselective blockade of T-type $\mathrm{Ca} 2+$ current in adult rat sensory neurons by a steroid that lacks gammaaminobutyric acid-modulatory activity. Mol Pharmacol 54:918-927.

Todorovic SM, Perez-Reyes E, Lingle CJ (2000) Anticonvulsants but not general anesthetics have differential blocking effects on different T-type current variants. Mol Pharmacol 58:98-108.

Todorovic SM, Jevtovic-Todorovic V, Meyenburg A, Mennerick S, PerezReyes E, Romano C, Olney JW, Zorumski CF (2001a) Redox modulation of T-type calcium channels in rat peripheral nociceptors. Neuron 31:75-85.

Todorovic SM, Jevtovic-Todorovic V, Mennerick S, Perez-Reyes E, Zorumski CF (2001b) $\mathrm{Ca}_{\mathrm{v}} 3.2$ channel is a molecular substrate for inhibition of T-type calcium currents in rat sensory neurons by nitrous oxide. Mol Pharmacol 60:603-610.

Todorovic SM, Meyenburg A, Jevtovic-Todorovic V (2004) Redox modulation of peripheral T-type $\mathrm{Ca} 2+$ channels in vivo: alteration of nerve injury-induced thermal hyperalgesia. Pain 109:328-339.

Ziegler D, Ametov A, Barinov A, Dyck PJ, Gurieva I, Low PA, Munzel U, Yakhno N, Raz I, Novosadova M, Maus J, Samigullin R (2006) Oral treatment with alpha-lipoic acid improves symptomatic diabetic polyneuropathy: the SYDNEY 2 trial. Diabetes Care 29:2365-2370. 